\title{
O DIREITO À CIDADE NO CONTEXTO DAS SMARTS CITIES: O USO DAS TIC'S NA PROMOÇÃO DO PLANEJAMENTO URBANO INCLUSIVO NO BRASIL
}

\author{
THE RIGHT TO CITY IN THE CONTEXT OF SMARTS CITIES: THE USE OF ICT IN THE \\ PROMOTION OF INCLUSIVE URBAN PLANNING IN BRAZIL
}

\author{
Patrícia Borba Vilar Guimarães ${ }^{1}$ \\ Douglas da Silva Araújo²
}

\begin{abstract}
Resumo
O presente estudo pretende investigar como o planejamento urbano numa abordagem bottomup está sendo implantado no Brasil, na construção de cidades inteligentes e democráticas, sob a ótica do direito à cidade, definido originalmente por Henri Lefebvre. Diante da estimativa que mais de $90 \%$ da população brasileira viverá em cidades no ano de 2030, surge a necessidade de pensar métodos e táticas estratégias e inovadoras para o planeamento urbano. As tendências ao uso das TICs (tecnologias de informação e comunicação) exercem papel significativo no século XXI, tanto na prestação de serviços públicos, quanto na gestão das cidades com vistas à participação ativa dos cidadãos. A exemplo de outras cidades, como Nanterre na França, que desenvolveram aplicativos e plataformas digitais como instrumentos de gestão urbana, visando proporcionar um engajamento cívico mais efetivo, é preciso analisar quais práticas com a mesma finalidade têm sido desenvolvidas no Brasil. Sob o prisma metodológico, foram empreendidos estudos de casos relativos às experiências adotadas pelas cidades de São Paulo, Pelotas e Belo Horizonte no que diz respeito a implantação de plataformas digitais em alguns setores da gestão urbana. As conclusões obtidas demonstraram que as TICs facilitam e contribuem com a participação social no âmbito do planejamento urbano (inclusivo) das smart cities.
\end{abstract}

Palavras-chaves: Smart cities. Tecnologias de informação e comunicação. Engajamento cívico. Planejamento urbano inclusivo.

\section{Abstract}

The present study intends to investigate how the urban planning in a bottom-up approach is being implanted in Brazil, in the construction of intelligent and democratic cities, from the point of view of the right to the city, originally defined by Henri Lefebvre. Given the estimated that more than $90 \%$ of the Brazilian population will live in cities in the year 2030, there is a need to

\footnotetext{
1 Doutora em Recursos Naturais pela Universidade Federal de Campina Grande (2010). Professora da Universidade Federal do Rio Grande do Norte, no Departamento de Direito Processual e Propedêutica (DEPRO). Líder da Base de pesquisa em Direito e Desenvolvimento (UFRN-CNPq) Docente vinculada ao Programa de Pós-graduação em Direito (UFRN-Mestrado Acadêmico) e ao Programa de Pós-graduação em Gestão de Processos Institucionais (UFRN- Mestrado Profissional). Membro do European Law Institute (ELI). E-mail: patriciaborb@gmail.com

${ }^{2}$ Especialista em Criminologia e Segurança Pública pela Faculdade Integrada de Patos (FIP). Mestrando em Direito pela Universidade Federal do Rio Grande do Norte (UFRN). Membro da Base de pesquisa Direito e Desenvolvimento (UFRN-CNPq).E-mail: douglasaraujojp@gmail.com
} 
think about strategies and innovative strategies and tactics for urban planning. Trends in the use of ICTs play a significant role in the 21st century, both in the delivery of public services and in the management of cities with a view to active citizen participation. As in other cities, such as Nanterre in France, which have developed digital applications and platforms as instruments of urban management, in order to provide a more effective civic engagement, it is necessary to analyze which practices with the same purpose have been developed in Brazil. From the methodological point of view, case studies will be undertaken regarding the experiences adopted by Brazilian municipalities. The conclusions obtained showed that ICTs are tools responsible for instrumentalizing social participation in the urban planning (inclusive) of smart cities.

Keywords: Smart cities. Information and communication technologies. Civic Engagement. Inclusive urban planning.

\section{NOÇÕES INTRODUTÓRIAS SOBRE O DIREITO À CIDADE: DA DEFINIÇÃO POLÍTICO- FILOSÓFICA AO CONCEITO JURÍDICO}

A definição do direito à cidade foi desenvolvida pelo sociólogo francês Henri Lefebvre em seu livro de 1968 Le droit à laville. Em singelas linhas, o autor conceitua o direito à cidade como um direito de não exclusão por parte da população das qualidades, benefícios e melhorias da vida urbana.

O direito à cidade nessa acepção lefebvriana nasce revestido de um ideário que remonta ao contexto das reformas urbanas parisienses, empreendidas pelo Barão de Haussmann, entre 1853 e 1870, que culminaram num processo de expulsão dos trabalhadores do centro da cidade de Paris, na França, remodelando-a sob o modo de produção capitalista.

Essa marginalização da classe pobre foi uma resposta das classes dominantes às jornadas operárias de 1848, como forma de frear a crescente democracia urbana, fomentada pelas lutas sociais, uma vez que naquele momento, apesar de embrionária, essa movimentação política representava uma ameaça aos interesses da classe burguesa (LEFEBVRE [1968] 2008, p. 22-23 apud TRINDADE, 2012, p. 141).

Filósofo marxista, Henri Lefebvre propõe em seu livro uma análise do direito à cidade sob um prisma político-filosófico, vinculando a participação cidadã ao processo de construção da cidade, servindo de incentivo aos eventos ocorridos em "Maio de 68", desrevestido, a princípio, de qualquer caráter jurídico. Para Lefebvre (2001, p. 22) a vida na cidade se baseia na diversidade e na coexistência dos diferentes, pressupondo encontros e confrontos das diferenças, conhecimentos e reconhecimentos recíprocos, inclusive no ponto de vista ideológico e político, dos modos de viver, dos "padrões" que coexistem na cidade. 
Sobre esse aspecto, TAVOLARI (2016, p. 104), analisando passagem do texto de Lefebvre, aduz que o sentido dado pelo autor ao direito à cidade reporta a um "direito 'não jurídico', relacionado a uma demanda moral fundada em princípios de justiça".

Nesse sentido, a proposta inicial do direito à cidade não era simplesmente incrementar o rol dos direitos humanos ou fundamentais, era sim de se contrapor ao processo de urbanização capitalista, em efervescência na França naquela época.

Numa compreensão teórico-social e contemporânea a Lefebvre, David Harvey discorrendo sobre o direito à cidade e o papel do homem sobre o espaço urbano alude que "a questão de que tipo de cidade se quer não pode ser divorciada do tipo de laços sociais, relação com a natureza, estilos de vida, tecnologias e valores estéticos que desejamos" (HARVEY, 2012, p. 74). O autor trata o direito em questão como a possibilidade de mudança da cidade, por meio de um processo de urbanização, com a participação de toda a coletividade (direito comum).

Interessante notar que Harvey incluiu a tecnologia como um dos recursos materiais comum a todos e proveniente do fenômeno da urbanização. Em que pese o tom crítico, o geógrafo britânico afirma que o uso de novas tecnologias é proveniente das lutas capitalistas por novos mercados, em que as inovações definem os novos desejos e necessidades da população. O autor assevera ainda que a tecnologia é responsável por reduzir o tempo de giro do capital, além de superar o conceito de "limite geográfico" (HARVEY, 2013).

Perceba-se que o direito à cidade, analisado sob a perspectiva de Lefebvre e Harvey, está intimamente ligado às formas de acesso de toda a população ao ambiente urbano e as chances dessa população participar do processo de transformação da cidade, contrário ao processo de excludente marginalização, proveniente do modo de produção capitalista do espaço.

Por conseguinte, diferenciando o sentido político-moral da dimensão jurídica do direito à cidade, Tavolari recorre a Marcuse, que propôs essa distinção separando os direitos na cidade no plural, de viés mais jurídico - direito à moradia, ao transporte, ao uso dos equipamentos públicos, à participação nas decisões locais, entre outros - e o direito à cidade no singular, que exigiria a completa transformação da cidade, a partir da instalação de uma organização social autogestionária, o que realmente foi proposto por Lefebvre (TAVOLARI 2016, p. 104).

Edésio Fernandes (2007) reconhece a importância da obra lefebvriana Le droit à laville, porém aduz que o conceito inacabado do direito à cidade, nessa compreensão mais jurídica, teria que ser buscado em Du Contrat de citoyenneté, também de autoria de Lefebvre, publicada em 1991. No citado texto, o direito à cidade é incluído numa lista de direitos humanos que 
ampliaria a Declaração de 1789 e estabeleceria as bases para um novo contrato social. Nessa obra, a função social da propriedade e a participação popular são interpretadas como conteúdo do direito à cidade.

Nessa perspectiva mais jurídica, mas sem se afastar do sentido filosófico, o direito à cidade representa a possibilidade de acesso e de transformação ao que o espaço urbano oferece; é a oportunidade de satisfação das diferentes necessidades da vida moderna e de autoafirmação do cidadão - qualidade do indivíduo que vive na cidade; é a reunião de diversos direitos fundamentais, que asseguram a dignidade da pessoa humana e a verdadeira democracia (FERREIRA, 2012).

Enquanto um direito metaindividual, BATTAUS e OLIVEIRA (2016, p. 82) afirmam que "o direito à cidade está sublocado à terceira dimensão dos direitos (humanos), e com amparo constitucional, é, fundamentalmente, um direito que os cidadãos têm a uma cidade hígida, a um ambiente harmônico e equilibrado e a um local que proporcione dignidade à pessoa". Nessa perspectiva, os autores sustentam que viabilizar o direito à cidade é também dar efetividade à dignidade humana e melhorar a qualidade de vida dos cidadãos.

Numa compreensão sistêmica e dimensional, é possível incluir o direito à cidade entre os direitos humanos fundamentais de terceira dimensão, isso porque esses direitos têm como sujeito de fruição a coletividade e como tal, o direito à cidade compreende "a progressiva implantação das condições materiais dependentes da evolução ou desenvolvimento dos espaços urbanos (ocupação, infraestrutura, regulação, etc.), o que exige uma prestação positiva do Estado, pois obrigado na ordem internacional à prática efetiva de políticas públicas, alocação de recursos econômico-financeiros, de pessoal, etc. outra, o direito à cidade, conferido à cidadania como direito fundamental positivado (MOLIONARO, 2010, p. 10)".

O direito à cidade, portanto, é entendido como um direito fundamental, com previsão constitucional, de natureza difusa, composto por outros direitos sociais e difusos, vinculado à dignidade da pessoa humana e regido pela solidariedade, que teve sua origem em demandas de movimentos sociais, especificamente os relacionados à reforma urbana, e contrapõe-se, muitas vezes, a direitos individuais, de conteúdo patrimonial e contratualista (GUIMARÃES, 2017, p. 636).

Nessa concepção jurídica há, destarte, uma ideia pulsante que o direito à cidade está relacionado com um ambiente urbano digno para todos os cidadãos, existindo uma espécie de cooperação entre seus moradores, seja na fruição dos benefícios, seja na divisão dos problemas e entraves encontrados na realização desse direito. Imbuído do ideal protecionista 
constitucional, o direito à cidade representa uma garantia de fruição por parte do indivíduo dos recursos materiais existentes nas cidades. É o acesso igualitário aos benefícios (infraestrutura, transporte público, moradia digna, saneamento, serviços públicos, etc.) decorrentes do processo de urbanização. Em outras palavras, o direito à cidade pode ser considerado um direito humano fundamental de terceira dimensão, seja por seu caráter de direito social lato sensu, seja por representar um direito transindividual, na medida em que visa à construção de um ambiente urbano pautado no bem estar coletivo, na igualdade de condições e na justiça social.

No ordenamento jurídico brasileiro, o direito à cidade, enquanto bandeira das lutas sociais, influenciou a edição do capítulo da "política urbana" presente na Constituição Federal de 1988. Durante a elaboração da Constituinte de 1988, movimentos sociais ligados ao ideário de redemocratização do Brasil enrijeceu a pauta da reforma urbana especialmente no final da década de 1970 e ao longo dos anos 80, criando o Movimento Nacional pela Reforma Urbana (MNRU), que apresentou uma emenda constitucional de iniciativa popular, subscrita por cerca de 130 mil eleitores de todo o país, com reivindicações ligadas especialmente aos movimentos populares de moradia, transporte, saneamento, entidades profissionais e sindicais, que, apesar de ter passado longe de sua incorporação integral, deu azo à criação do capítulo específico sobre a reforma urbana, pela primeira vez na história constitucional brasileira (TRINDADE, 2012). Esse debate em torno da questão urbana, fomentado principalmente pelos movimentos sociais e políticos, teve início no Brasil ainda na década de 1960, desarticulando-se durante o governo militar, porém ressurgindo como já dito com as mobilizações pela redemocratização do país.

Imbuído desse sentido jurídico-constitucional, o direito à cidade, como princípio implícito contido na Carta Magna de 1988, especificamente no capitulo denominado "Política Urbana", é tratado como garantia constitucional, representando uma prerrogativa a todos os brasileiros no usufruto da estrutura urbana e dos espaços públicos de suas cidades. Ainda sob esse viés constitucional, conforme dicção dos artigos 182 e 183, o direito à cidade permite aos municípios a instauração de uma política de desenvolvimento urbano a fim de ordenar o pleno desenvolvimento das funções sociais da cidade e garantir o bem-estar de seus habitantes (art. 182, caput, Constituição Federal).

Mais tarde, a criação da lei 10257/2001, denominada como Estatuto da Cidade, representou talvez o maior avanço na conquista de prerrogativas que norteassem a política urbana no Brasil, estabelecendo "normas de ordem pública e interesse social que regulam o uso 
da propriedade urbana em prol do bem coletivo, da segurança e do bem-estar dos cidadãos, bem como do equilíbrio ambiental" (art. $1^{\circ}$ ). A referida lei representa, sobretudo, uma valorização do princípio da dignidade da pessoa humana, posicionando-o mais uma vez no cume do ordenamento jurídico-constitucional, mediante a efetivação do direito à cidade.O estatuto também representa uma resposta forte às necessidades urbanas no mundo atual e, em parte, mostra uma preocupação com a distribuição desigual dos recursos urbanos (ROLNIK, 1997).

Segundo Fernandes (2007) o Estatuto da Cidade representou um desenvolvimento importante na materialização do direito à cidade em termos legais, e não apenas enquanto uma noção política.

O Estatuto da Cidade, além de regulamentar o capítulo da Constituição relativo à política urbana, veio evidenciar a importância da gestão democrática municipal como um mecanismo implementador do princípio da dignidade da pessoa humana e como instrumento importante da cidadania, a partir da participação da população na aprovação coletiva dos projetos para a cidade, visando reverter à situação de desequilíbrio vivenciada na grande maioria dos centos urbanos, em que grande parte dos habitantes permanece à margem da infraestrutura e dos serviços públicos municipais (gerando conceitos como cidade formal incluídos - e cidade informal - excluídos). A gestão democrática da cidade, como pregada pela legislação urbanística, "garante que a realização das ações municipais de acordo com as funções sociais do núcleo urbano (moradia, lazer, mobilidade, transporte) possam ser fiscalizadas não apenas após a concretização dos planos de ação, mas desde o momento de sua programação orçamentária e planejamento administrativo" (MOURA, 2016, p. 1090). De tal modo, nessa "nova" roupagem política urbana, prepondera-se o "direito de cada cidadão em participar do planejamento a respeito do desenvolvimento da cidade, garantindo que ela seja sustentável para esta e para as futuras gerações" (SANTIN e MARANGON, 2008, p. 92).

Perceba-se que o Estatuto da Cidade pretende ampliar a participação social na gestão urbana dos municípios, instituindo instrumentos eficazes para induzir o Poder Público a agir com maior transparência, tendo em vista a inegável carência da participação dos cidadãos nas decisões políticas municipais (SANTIN, 2003). Do ponto de vista jurídico, "o Estatuto da Cidade salvaguarda o meio ambiente urbano justo, equilibrado e sustentável, estabelecendo que toda a atividade econômica deve ter especial planejamento por parte do administrador público, observando-se os limites de sustentabilidade ambiental" (SANTIN e MARANGON, 2008, p. 91). 
Diante o rápido e desgovernado processo de urbanização no mundo e no Brasil, o Estatuto da Cidade inaugura uma agenda democrática de governo com a participação popular na gestão administrativas dos municípios. Estima-se que em 2014 a população urbana global era de 54\%, o que deverá crescer para 70\% até 2050 (WORLD URBANIZATION PROSPECTS, 2014). Em notícia divulgada no site do Governo Federal do Brasil ${ }^{3}$, avalia-se que mais de $90 \%$ da população brasileira viverá em cidades no ano de 2030. Diante desse cenário, é essencial que as cidades estejam preparadas para o recebimento dessas massas, revelando a importância do planejamento urbano.

Esse crescimento exacerbado da população urbana trouxe inúmeros problemas às cidades. Especialmente na América Latina, o crescimento do número de assentamentos irregulares e outras formas precárias de moradia, impulsionadas pela segregação social, característica do modo de produção capitalista do espaço, evidenciam o caos experimentado diariamente pelos cidadãos, principalmente no que diz respeito à fruição dos serviços públicos.

Diante essa desordem instaurada nas cidades, surge a necessidade de pensar métodos e táticas estratégias e inovadoras para o planejamento urbano. As tendências ao uso das TIC (tecnologia de informação e comunicação) exercem papel significativo no século XXI, uma vez que esta tecnologia impacta a urbanização, a logística e os negócios, a estrutura em rede das cidades, os serviços básicos, os sistemas de gerenciamento ambiental, as operações governamentais dependentes de dados, como finanças, e, principalmente, as interações entre pessoas (ITU, 2014). Porém, na busca fidedigna de concretização do direito à cidade, o desafio principal é democratizar o acesso a essas tecnologias, com fundamento central no homem e no fito de incluí-lo no processo de transformação do espaço urbano, predominantemente capitalista.

A par dessa discussão inicial, o presente estudo tem por objetivo avaliar experiências brasileiras de uso das TICs no âmbito da gestão urbana, que visem promover uma participação social mais ampla. Como metodologia, a pesquisa detém caráter descritivo, tendo sido realizados estudos dos casos das plataformas digitais implantadas nas cidades de São Paulo/SP, Pelotas/RS e Belo Horizonte/MG, levando em consideração os dados constantes nos sites das respectivas das plataformas, bem como nos sites das prefeituras as quais os programas estão vinculados. Após um levantamento documental, feito com base em relatórios e demais documentos constantes nos sites citados, foram feitas as respectivas deduções sobre material

${ }^{3}$ Disponível em: <http://www.brasil.gov.br/cidadania-e-justica/2016/10/em-2030-90-da-populacaobrasileira-vivera-em-cidades>. Acesso em: 12 mai. 2018. 
coletado, visando, sobretudo, promover uma correlação com o direito à cidade, de proposta inicial desenvolvida por Henri Lefebvre, a fim de substanciar a discussão sobre planejamento urbano inclusivo - e digital.

\section{PLANEJAMENTO URBANO, CIDADES INTELIGENTES E DIREITO À CIDADE}

Inicialmente, antes de adentrar no estudo do planejamento urbano na perspectiva das cidades inteligentes, deve-se ponderar acerca do conceito desta última.

Os professores Patrícia Borba e Yanko Xavier, discorrendo sobre a definição de smart cities numa acepção voltada para o Direito, apresentam uma tríade de princípios e fundamentos que funcionam como aspectos na conceituação das cidades inteligentes, quais sejam: o aspecto ambiental, o aspecto relacionado à inovação tecnológica e comunicação digital, além do aspecto direcionado ao desenvolvimento humano (GUIMARÃES e XAVIER, 2016).

De modo sucinto, o aspecto ambiental das cidades inteligentes está ligado à gestão dos recursos naturais, por meio de programas e ações sustentáveis, visando à preservação e equilíbrio do ecossistema urbano. Por sua vez, a inovação tecnológica e comunicação digital relacionam-se com a inserção das tecnologias de informação e comunicação (TICs) como parte integrante na construção de um ambiente urbano com serviços e infraestrutura mais eficientes. Por fim, o aspecto desenvolvimentista diz respeito à capacidade dessas cidades inteligentes em promover a gestão urbana atenta aos novos anseios da população influenciada pela globalização econômica, sob um modo de governança compartilhada e transparente, fazendo uso de ações céleres e políticas públicas de planejamento mais eficazes, melhorando assim a qualidade de vida dos citadinos.

Numa compreensão sistêmica dos aspectos listados acima, têm-se que as smart cities fazem uso da tecnologia da informação em suas estruturas físicas para aprimorar conveniências, facilitar a mobilidade, aumentar a eficiência, conservar energia, melhorar a qualidade do ar e da água, recuperar-se mais rapidamente de desastres, coletar e organizar dados para tomar melhores decisões, destinar recursos com mais efetividade, compartilhar dados para aprimorar a colaboração de entidades e diferentes domínios, enfim, para identificar problemas e resolvê-los rapidamente (STRAPAZZON, 2009, p. 94).

Portanto, a expressão cidade inteligente tem sido relacionada ao emprego eficiente de tecnologias de informação e comunicação (TICS) com o uma ferramenta para melhorar a infraestrutura e serviços da cidade, trazendo, consequentemente, melhor qualidade de vida 
para a população (GAMA; ÁLVARO; PEIXOTO, 2012). Embora careça de uma definição unanimemente aceita, as cidades inteligentes possuem, com já dito, "características amplamente reconhecidas, as quais se referem, de modo geral, a um ideal que se articula em torno de três eixos: o desenvolvimento econômico (humano), a redução da pegada ambiental e a melhoria da qualidade de vida dos citadinos, valendo-se das tecnologias disponíveis, em particular das digitais" (SOUPIZET, 2017, p. 10).

Após essa breve análise do conceito das smart cities, é imperioso entender o seu papel no planejamento urbano de modo associado à compressão dada ao direito à cidade.

A resposta da assertiva acima colocada reveste-se totalmente de um ideário político e ideológico, isso porque a compressão dada ao direito à cidade no contexto das cidades inteligentes não pode fugir da lógica democrática apontada por este trabalhado, especialmente quando se falou sobre a construção do direito à cidade.

O direito à cidade parte de uma lógica democrática de acesso aos recursos materiais presentes no espaço urbano, consubstanciada na fruição isonômica dos serviços de mobilidade, transporte, moradia, segurança, saneamento e outras benesses que garantam à população uma boa qualidade de vida nas cidades. Veja que o conceito, como ora colocado, se contrapõe a qualquer espécie de prática marginalizadora e discriminatória.

Contudo, experiência diversa se viu na prática. O processo de urbanização no Brasil, logo no início do século XX, devido à rápida industrialização, a qual funcionou como um dos principais fatores para o deslocamento da população da área rural em direção à área urbana, processo conhecido por êxodo rural, provocou a mudança de um modelo agrário-exportador para um modelo urbano-industrial. Atualmente, mais de $80 \%$ da população brasileira vive em áreas urbanas, o que equivale aos níveis de urbanização dos países desenvolvidos (GOBBI, 2016).

A atração dessas populações para os centros urbanos se deu de forma desgovernada, tendo em vista que as cidades não possuíam infraestrutura suficiente para recebê-las, sendo totalmente carentes em relação às políticas receptivas (habitação, moradia, segurança, etc.) dessas massas.

Igualmente, o aprofundamento da industrialização no Brasil, após o fim da segunda guerra mundial, difundiu ainda mais o capitalismo, fomentando a entrada do capital estrangeiro, notadamente na década de 50 , com uma forte onda de importação de capitais advindos da expansão mundial de empresas multinacionais, em busca de novos mercados e novas fontes de lucro. 
A difusão do capital estrangeiro significou ainda uma oposição à expansão do capital estatal e aos privilégios concedidos à agricultura de exportação, além de ter proporcionado a manutenção da correlação de forças entre as classes dominantes e o delicado equilíbrio de alianças formado, fortalecendo a discussão de reformas profundas quanto às fontes de financiamento e às reformas sociais, em um país que passaria por uma forte urbanização e reforçaria a miséria e a desigualdade regional (FAUSTO Org., 2007a).

Nesse cenário, o direito à cidade não passou/passaria de uma pretensão utópica.

No final do período militar, em que os movimentos sociais pela redemocratização do país ganhavam força, em especial aqueles ligados às pautas de reforma urbana (moradia, mobilidade, etc.), enxergou-se no país uma real chance de trazer a política urbana à discussão na Assembleia Nacional Constituinte, o que se concretizou por meio da Emenda Popular da Reforma Urbana, como já falado.

Com a promulgação da Constituição Federal do Brasil de 1988, e posteriormente a edição do Estatuto da Cidade, instrumentos legais que significaram o maior avanço legislativo na regulamentação da política urbana, enrijeceu-se a discussão do direito à cidade com o fito primordial de promover o pleno desenvolvimento das funções sociais da cidade em prol do interesse coletivo.

Revivida essa discussão inicial, pondera-se finalmente sobre a possiblidade de entender o papel das smart cities no planejamento urbano associado à compressão dada ao direito à cidade.

A princípio, buscando solucionar o questionamento acima, é essencial entender as cidades inteligentes a partir do equilíbrio entre três princípios basilares que compõem o seu conceito, erigidos com fundamento nos aspectos ambiental, tecnológico e desenvolvimentista.

Por conseguinte, acredita-se que a melhor forma de entender o papel das smart cities no planejamento urbano com observância ao conceito do direito à cidade, será a partir do alinhamento da perspectiva das cidades inteligentes ao desenvolvimento das funções sociais da cidade na busca de uma convergência entre ambas. Com a primeira denotando o envolvimento dos cidadãos no processo de inovação urbana, e a segunda significando a priorização de funções destinadas a combater e reduzir as desigualdades sociais e territoriais, a combater e eliminar a pobreza, a promover a justiça social, a satisfazer os direitos fundamentais das pessoas de terem condições de vida digna (LIBÓRIO e SAULE JÚNIOR, 2017). Visando evitar novos processos segregacionistas da vida urbana, a cidade inteligente deve ser pensada em 
conformidade com o direito à cidade, na proposição inicial lefebvriana (PALIOLOGO e GOMES, 2017, p. 19).

Mas será que é possível promover inovação urbana inclusiva nas cidades? A resposta a essa indagação ficará para próxima seção.

\section{SMART CITIES E INOVAÇÃO URBANA INCLUSIVA}

$\mathrm{Na}$ atualidade, a tecnologia ocupa espaço central na sociedade do conhecimento e traz intrinsecamente a questão da ampliação do trabalho imaterial produtivo, com especial relevância aos aspectos da comunicação, do marketing, da publicidade e das marcas como importantes ativos das sociedades empresárias, como formas de diferenciação em um mercado marcado pelo fenômeno da globalização (...). Entretanto, existem consequências danosas ao mundo do trabalho advindas dessa mesma lógica de orientação, como, por exemplo, "a erosão do trabalho regulamentado, as terceirizações, o trabalho assalariado travestido de empreendedorismo e cooperativismo (desvirtuamento da ideia básica de cooperativa, resultando na prática em formação de cooperativas patronais), a formação do chamado "terceiro setor", o desmonte da legislação protetora do trabalho e o aumento dos mecanismos de extração do sobretrabalho" (PORTILHO e SOUSA, 2014, p. 176).

Nesse cenário, a exploração tecnológica pelas empresas está a contribuir para a criação de um mundo desigual, onde impera a polarização econômica, social e territorial. Problemas como a pobreza, as desigualdades e discriminação têm estado ausentes do debate. Além do mais, aqueles que foram excluídos do processo econômico deixaram de ter voz ativa na construção da cidade (SELADA, 2017).

Tecidas essas breves considerações, a indagação que enseja esta seção é: como criar uma cidade inteligente sob uma ótica inclusiva?

O planejamento urbano numa abordagem "bottom-up" (de baixo para cima) é um dos primeiros passos para uma discussão horizontalizada da cidade, dando espaço ao "cidadão inteligente", que assume um papel participativo e colaborativo na gestão das smart cities, além do incentivo às iniciativas locais empreendidas por startups na busca de soluções criativas e inovadoras para as cidades inteligentes.

Nesse contexto, a questão que se coloca é a da renovação da ação pública local com a crescente importância das Civic Tech (tecnologia cívica), assim como a da transformação da relação entre a política, o cidadão e os territórios (SOUPIZET, 2017, p. 40). As civic tech ou civic 
technology representam o uso da tecnologia, principalmente tecnologia da informação, no envolvimento e participação dos cidadãos na gestão da cidade, visando o desenvolvimento e a melhoria da infraestrutura urbana. As civic tech fazem uso das civic applications, que são softwares (aplicativos) que permitem essa participação dos cidadãos das decisões governamentais, de forma a promover o engajamento cívico nas políticas públicas, o que só será possível a partir da educação digital e conscientização política da própria população.

Ponderando sobre o desenvolvimento econômico e tecnológico e a inclusão social, o geógrafo Iván Tartaruga (2016, p.11) sustenta que o potencial de aumento das inovações tecnológicas na América Latina, por meio de inovações inclusivas - também capazes de expandir o mercado de consumo - requer, ao mesmo tempo, o incremento de inovações sociais, porquanto a inclusão econômica deve acompanhar mudanças profundas na estrutura da sociedade, caso contrário, todo o processo poderia ser prejudicado pela falta de consistência e continuidade. $O$ autor alude também que os processos de inovação social tendem a enfrentar a dinâmica da exclusão social e, para tanto, esse tipo de inovação mobiliza recursos necessários e disponíveis (humano, sócio institucional, organizacional e financeiro) para transformar os mecanismos de exclusão em estratégias e processos mais inclusivos.

O autor ainda conceitua inovações inclusivas como aquelas inovações orientadas para a produção de novos produtos e/ou processos para atender as necessidades de pessoas de baixa renda, sendo baseadas nos esforços de governos, empresas, organizações não governamentais ou pessoas em geral, mesmo aqueles com pouca ou nenhuma educação formal (TARTARUGA, 2016, p.10).

Nesse contexto de inovações inclusivas, as startupspoderão assumir relevante papel, sobretudo quando o autor conclui pela adoção de um modelo duplo integrado de desenvolvimento para América Latina, atuando de cima para baixo, no sentido de introduzir industrias baseadas em recursos naturais da região, e de baixo para cima, visando todo o território de cada país, promovendo as atividades produtivas realizadas nos mercados mais apropriados (aglomerações especializadas em nichos de mercados) (TARTARUGA, 2016).

Promover essa inclusão digital é, sem sombra de dúvida, um dos maiores desafios para o Poder Público no desenhar dessas cidades inteligentes. Considerando que a provisão de soluções urbanas baseadas no uso de tecnologias é um dos componentes fundamentais para a construção de uma smart city, a inclusão digital é uma questão-chave para que a população como um todo possa se beneficiar das oportunidades ofertadas. Do contrário, as iniciativas de 
smart city poderiam levar ao acirramento das desigualdades tanto no acesso às TIC, como também no acesso aos serviços urbanos (SMART CITIES, 2017).

Algumas experiências dessas práticas inclusivas no âmbito do planejamento urbano nas cidades inteligentes já são adotadas pelo mundo, as quais fazem uso das TICs na gestão dessas cidades a fim de promover o debate público cada vez mais democrático, através de consultas, sondagens, votos consultivos e submissão de projetos aos cidadãos (SOUPIZET, 2017, p. 41). Exemplos dessas práticas tecnológicas inclusivas são vários municípios franceses, como Nanterre, que lançaram o site participez.nanterre.fr, ou o aplicativo fluicity, ou ainda o vooteradotado pela cidade deBougival ${ }^{4}$ (SOUPIZET, 2017, p. 41). Dentre eles, o Fluicity ${ }^{5}$ se apresenta como padrão de governança para todos os atores públicos que querem colocar os cidadãos no coração da política.

Melhorar os serviços prestados mediante a contribuição dos cidadãos é principal objetivo dessas plataformas. Há também vários exemplos nesse sentido, como OpenStreetMap, Clearaway zone, DansMaRue6(SOUPIZET, 2017, p. 41). Esses exemplos estão, em geral, associados ao crowdsourcing (colaboração coletiva).

O termo crowdsourcing, nesse contexto, está relacionado com o "aparecimento de sites que se utilizam da audiência/multidão (crowd) como fonte (source) de conteúdo ou mão de obra atuante e decisiva para a existência do mesmo" (SOUSA, 2012, p. 76). O crowdsourcing dá ensejo às plataformas colaborativas (sites), em que os próprios usuários são responsáveis pela alimentação/fornecimento de dados.

Sousa (2012, p. 80) cita como exemplo de experiências colaborativas na Internet as páginas denominadas wiki, como Wikipédia, e aponta "como início desse movimento, [...] sites como Slashdot e blogs surgidos na virada do milênio XX para o XXI (sic)". Sousa (2012) ainda cita, dentre outros, portais de jornalismo cidadão, sites de compartilhamento de mídias e jogos virtuais, fóruns, programas de mensagem instantânea e redes sociais.

Agregando esse novo fenômeno à ideia de planejamento urbano participativo, pode-se concluir que o crowdsourcing apresenta-se como uma ferramenta extremamente útil à sua consecução, ao passo que representa um modelo original de organização que coloca a população no centro do processo de produção (SCHENK e GUITTARD, 2012).

\footnotetext{
${ }^{4}$ Disponível em: <http://vooter.co>. Acesso em: 14 fev. 2018.

${ }^{5}$ Disponível em: <https://www.flui.city/>. Acesso em: 14 fev. 2018.

${ }^{6}$ Disponível em: <www.paris.fr/dansmar>. Acesso em: 14 fev. 2018.
} 
Brabham (2009) alude que o crowdsourcingé um modelo complexo e legítimo de resolução de problemas, capaz de agregar talentos e reduzir custos e tempo necessários para resolver um problema. Assim, na visão do autor, o crowdsourcing pode ser utilizado para fomentar a participação do público no planejamento urbano. Segundo ele, em essência, qualquer projeto de planejamento urbano baseia-se em um problema, e se houver um problema que pode ser moldado de forma clara, e se todos os dados relativos podem ser disponibilizados, esse problema pode ser crowdsourced(contar com os serviços de um número de pessoas através da Internet).

Portanto, o crowdsourcing surge como uma ferramenta moderna a ser utilizada pelos gestores públicos, empresas privadas, órgãos não governamentais e todos os atores envolvidos na discussão em torno do planejamento urbano inclusivo, ante sua utilidade na coleta e otimização de dados, e da possibilidade de inserção da população (destinatária final dos serviços públicos) nas políticas voltadas à melhoria da vida na cidade (inteligente), proporcionando um engajamento que vai desde o reconhecimento de problemas urbanos até as chances de participar propondo soluções. A participação do cidadão é, conforme Komninos (2008 apud CURY \& MARQUES, 2017, p. 110), "o início do processo de constituição de uma cidade inteligente".

\section{PLANEJAMENTO URBANO, INCLUSÃo E TECNOLOGIA: PROJETOS E PRÁticAS BOTTOM-UP NO BRASIL}

Após discorrer sobre a utilidade do crowdsourcing no planejamento urbano participativo, no campo das cidades inteligentes, se faz necessário investigar como essa ferramenta está sendo implantada no Brasil, a partir de experiências bottom-up.

O primeiro exemplo a ser citado no que diz respeito ao uso das TIC's no planejamento urbano (crowdsourcing), é a plataforma digital participativa "Gestão Urbana SP7", desenvolvida com vistas à revisão do Plano Diretor Estratégico da cidade de São Paulo/SP (Lei n.o 16.050 de 31 de julho de 2014). Esse processo de revisão buscou, dentre outras finalidades, ampliar a participação popular, tanto por meio de atividades presenciais (seminários, oficinas, audiências públicas e diálogos com segmentos), quanto por meio de plataformas participativas digitais, visando à promoção de um processo democrático: "O debate com a sociedade significa um

\footnotetext{
${ }^{7}$ Disponível em: <http://gestaourbana.prefeitura.sp.gov.br/>. Acesso em: 14 mai. 2018.
} 
substancial incremento de qualidade e o amadurecimento necessário que uma Lei de tamanha abrangência deve ter" (PREFEITURA DE SÃO PAULO, 2013).

A plataforma "Gestão Urbana SP" tinha o papel de informar ao cidadão sobre a revisão participativa e suas etapas (quatro) de maneira simples, comunicar as últimas notícias e a agenda de atividades, permitir acesso a documentos úteis para a revisão, como leis e apresentações além de permitir uma participação ativa através de contribuições da sociedade civil (PREFEITURA DE SÃO PAULO, 2014).

Segundo Alves e Brelàz (2015, p. 19) essa plataforma digital foi criada como um software livre, o que é uma forte tendência quando se discute abertura, transparência e governo eletrônico. Desde o inicio da revisão do plano diretor, foram disponibilizadas fichas online que permitiam o envio de propostas pela internet, feitas para quem possuía conhecimento técnico. De acordo com as autoras foi proposto também um mapeamento colaborativo que tornou possível apontar diretamente o que estava bom e o que precisava melhorar na cidade, sugerindo ideias.

Com relação aos resultados, os mecanismos digitais levaram ao maior número da participação, já que no processo de revisão 44\% das contribuições foram feitas através da plataforma digital. Trata-se de um número relevante para o total de contribuições e ao mesmo tempo pequeno em relação a uma cidade do porte de São Paulo. As contribuições são expressivas se comparadas com as participações presenciais (off-line), mas ao mesmo tempo de pequena proporção para o tamanho da população do território. Com isso, fica nítido que os meios digitais podem facilitar, mas estes por si só não irão gerar a participação. É necessária a conscientização da importância da discussão de políticas públicas (ALVES \& BRELÀZ, 2015, p. 22).

Outro exemplo de uso do crowdsourcing em estratégias voltadas ao planejamento urbano foi a criação do "blog participativo" para elaboração do Plano Local de Habitação de Interesse Social (PLHIS) de Pelotas $/ \mathrm{RS}^{8}$. Em sua página de apresentação, o blog se propõe em acompanhar todas as atividades desenvolvidas durante as etapas de elaboração do PLHIS, possibilitando ao público interessado colher informações e comentar a respeito de temas pertinentes.

O PLHIS de Pelotas/RS é considerado um exemplo inovador de emprego dos recentes avanços tecnológicos da Internet e dos SIG (Sistemas de Informação Geográfica na Internet)

\footnotetext{
${ }^{8}$ Disponível em: <http://plhispelotas.blogspot.com.br/>. Acesso em: 14 fev. 2018.
} 
para a participação pública, pois disponibiliza diversos canais de interação: a) Blog que descreve todas as atividades desenvolvidas durante as etapas de elaboração do PLHIS, como o mapa com as fotos georeferenciadas das visitas às áreas com problemas; b) Rede social que já conta com mais de 400 amigos, e possibilita o bate-papo, envio de mensagens entre os participantes, fóruns de discussão, enquetes, etc.; c) Twitter que fornece alerta de notícias sobre o PLHIS, e; d) Mapa participativo ${ }^{9}$ no qual os usuários podem postar eventos no mapa, o que possibilita a coleta de informações georeferenciadas segundo a percepção dos moradores (BUGS et al, 2015).

Em diagnóstico exposto em abril de 2013, apresentado pelos técnicos da 3C Arquitetura e Urbanismo, comprovou-se um déficit habitacional da cidade de Pelotas em 13.598 unidades habitacionais urbanas e rurais. A cidade destacou-se também no diagnóstico por apresentar características diferentes de cidades do mesmo porte, pois Pelotas possuía 113 mil residências cadastradas no IPTU e seu déficit habitacional era de $11,93 \%$, sendo que, se comparada a cidades do mesmo porte, o índice médio de carência dessas cidades é de apenas 6\% (PLHIS PELOTAS, 2013).

Diante esse cenário de caos, um grande desafio pairava sobre Poder Público local, sobretudo no que diz respeito à criação de programas e ações para tentar solucionar esses problemas habitacionais. O uso da plataforma digital "PLHIS PELOTAS" (blog) foi uma estratégia na busca de dados e propostas junto à sociedade civil.

Por último, a implantação do Orçamento Participativo Digital em Belo Horizonte/MG também constituiu exemplo da utilização do crowdsourcing no planejamento urbano. 0 orçamento participativo representa um forte instrumento de participação dos cidadãos no processo de tomada de decisão por parte da administração pública (smart governance), constituindo uma dimensão de análise para fins de inclusão de uma cidade na definição "inteligente" (CASTRO, 2015).

Em 2006 foi implantada essa nova modalidade de orçamento participativo em Belo Horizonte, O OP Digital ${ }^{10}$, via participação virtual, contrapondo-se aos processos até então existentes de votações presenciais - de participação off-line. Dentre os desafios de sua implementação, incluiu-se a necessidade de incorporar novos segmentos da população às deliberações do OP, em especial a classe média e a juventude. O OP Digital foi a primeira experiência mundial de uso da internet por um governo local como instrumento deliberativo de

\footnotetext{
${ }_{9}^{9}$ Disponível em: <wikimapps.com/index.php/a/4e3ad33ac24af>. Acesso em: 14 fev. 2018.

10 Disponível em: <www.pbh.gov.br/opdigital>. Acesso em: 14 fev. 2018.
} 
parte do orçamento público (em contraposição a seu uso mais frequente como instrumento consultivo) (NABUCO et al, 2009, p. 141).

Ao disponibilizar mecanismos virtuais para escolha dos empreendimentos a serem realizados com recursos do OP, através da internet e telefonia, a administração pública de Belo Horizonte tinha dois objetivos principais, ampliar a participação, incorporando novos atores aos processos decisórios da cidade que tradicionalmente não participam como a classe média e os jovens e alocar fundos específicos para obras estruturantes, relevantes para a cidade como um todo e que beneficiam um percentual expressivo da população, em contraposição às obras eleitas no OP Regional (de deliberação presencial - assembleias), que atendem demandas locais, de uma rua, bairro ou região, e que partem de uma visão territorial fragmentada da cidade (NABUCO et al, 2009, p. 142).

Perceba-se que o uso dessa espécie de civic applications na gestão do orçamento participativo proporciona uma discussão mais ampla e consequentemente mais democrática, ao passo que consegue chegar com mais facilidade às variadas camadas e setores sociais, além de promover uma otimização do tempo e de gastos como, por exemplo, com transporte e demais despesas comuns às formações de audiências públicas, conselhos deliberativos e outras formas de deliberação presencial.

Na sua segunda edição, em 2008, o OP Digital submeteu à votação cinco obras estruturantes para a cidade, todas visavam melhorar a circulação viária (...). Cada eleitor teve direito a um único voto, o qual pode ser feito por internet através do acesso ao endereço eletrônico www.pbh.gov.br/opdigital, ou por telefone, fixo ou móvel, através de ligação gratuita para o número 08007232201 (...) (NABUCO et al, 2009).

Para possibilitar o amplo acesso da população ao processo de votação, duas estratégias foram fundamentais. A primeira foi a possibilidade de votar a partir de qualquer telefone (celular, fixo ou público) através de ligações gratuitas, para o eleitor, e pagas pelo governo municipal, que permitiu maior participação das pessoas sem acesso à internet. A segunda foi a articulação com programa municipal de Inclusão Digital, que possibilitou o uso no processo de votação de mais de 270 pontos públicos de acesso à internet já existentes (...). A sociedade civil também se mobilizou e vários outros pontos de votação foram disponibilizados à população em lojas do comércio, escolas, shoppings, dentre outros (NABUCO et al, 2009, p. 144).

Quanto aos resultados, foram contabilizados 113.383 votos no Orçamento Participativo Digital 2008, o que corresponde a $8 \%$ da base eleitoral de BH. Do total de votos, $89,87 \%$ foram computados pela internet e 10,13\% por telefone. A título de comparação, convém destacar 
que, no processo do Orçamento Participativo Regional (participação off-line) realizado durante o ano de 2008 (Orçamento Participativo 2009/2010) participaram 45 mil pessoas, durante 08 meses, para deliberarem sobre um orçamento de $\mathrm{R} \$ 110$ milhões. "Estes dados revelam que, embora o Orçamento Participativo Digital deliberasse sobre um orçamento que equivale a apenas $45 \%$ do valor destinado ao OP Regional, contou com 2,5 vezes mais eleitores que o processo presencial" (NABUCO et al, 2009, p. 150).

Diante tais dados, é válido acrescentar que o acesso à internet em 2008 detinha uma configuração totalmente diversa da atual, ampliada especialmente pelo uso de celulares e smartphones. Um estudo feito pelo IBGE em 2015, e revelado no final de 2016, mostrou que mais de $92 \%$ dos acessos à Internet no Brasil são feitos através de dispositivos móveis, na grande maioria pelos aparelhos celulares. Esse crescimento consolidou os smartphones como a principal forma de acessar a internet nos domicílios brasileiros, superando pela primeira vez os computadores. E ainda, a título de comparação com o ano anterior ao da pesquisa, 2014, o acesso à internet pelo celular cresceu 11,7\% (IBGE, 2015).

Imagine esses dados comparados à realidade do ano de 2008, quando foi realizada a segunda edição do OP Digital, em Belo Horizonte. Certamente, o sucesso da iniciativa bottomup teria sido muito maior caso executada na atualidade.

As experiências relatadas ainda são pioneiras no Brasil quando se fala no uso das TIC's no planejamento urbano, porém, ainda existem percalços a serem superados, como também questões a serem debatidas, que vão desde a forma de coletar dados/informação junto à sociedade civil, passando pela etapa de validação desses dados, até à análise dos resultados.

Em estudo realizado por Burg e Reis (2016) sobre o tema em discussão, objetivando avaliar a aceitação por parte dos especialistas acerca da participação pública e da utilização de novas tecnologias, demonstrou-se que essas novas metodologias participativas pode auxiliar significativamente na difícil tarefa de acessar e incorporar o conhecimento local no planejamento urbano, além de poder permear todo o processo de planejamento, desde a coleta de informações sobre a percepção da população acerca de determinado tema, antes mesmo da elaboração das propostas, até o monitoramento da opinião da população ao longo do processo.

Por fim, alguns benefícios podem ser extraídos da análise das plataformas digitais acima, as quais utilizarão o crowdsourcing em estratégias voltadas ao planejamento urbano: 1ํ) participação social mais ampla, alcançando um maior número de pessoas e/ou usuários; 2ㅇ) 
elaboração de propostas mais democráticas; 3ํ) otimização de tempo e redução gastos; 4ํ) soluções urbanas bottom-up.

\section{CONCLUSÃO}

Pretendeu-se com este estudo fazer ponderações sobre a noção original do Direito à Cidade, proposta por Lefebvre, concluindoque sua aplicação no contexto das smart cities, não poderá se dissociar do ideal democrático de sua gênese. Daí decorre as ideias de planejamento urbano inclusivo, do crowdsourcing, das soluções urbanas bottom-up, sustentadas neste trabalho.

De tal modo, as cidades inteligentes se justificam na ótica lefebvriana, desde que sustentáveis, criativas e democráticas, na medida em que fazem uso de tecnologia de informação e comunicação (TICS) no planejamento urbano e participação dos cidadãos. No desiderato de construção das cidades inteligentes e democráticas, a educação digital e o fomento à conscientização política representam passos iniciais nesse longo caminho.

Viu-se ainda que as TICS são ferramentas responsáveis por instrumentalizar a participação social no âmbito do planejamento urbano através de civic applications, como os exemplos citados das "Gestão Urbana SP" (http://gestaourbana.prefeitura.sp.gov.br/);

"PLHIS PELOTAS" (http://plhispelotas.blogspot.com.br/); e "OP Digital" (www.pbh.gov.br/opdigital), implementadas, respectivamente, pelas Prefeituras da capital São Paulo, na cidade de Pelotas no Estado do Rio Grande do Sul, e Belo Horizonte, capital de do Estado de Minas Gerais.

No que diz respeito aos resultados, sobretudo num comparativo com as participações presenciais, as experiências de uso das plataformas digitais em São Paulo e Belo Horizonte alcançaram maior adesão no que diz respeito à participação social. Em São Paulo, apesar dos cidadãos terem outras formas de participação da revisão do Plano Diretor (participação offline), 44\% das contribuições foram feitas através da plataforma "Gestão Urbana SP". Já em Belo Horizonte, o Orçamento Participativo Digital (2006) contou com 2,5 vezes mais eleitores do que o processo presencial do Orçamento Participativo Regional (2008), ressalvadas suas devidas proporções e previsões. Em Pelotas, apesar de não terem sido encontrados dados de outros processos participativos presenciais de mesma finalidade, que permitissem uma comparação mais equânime, a plataforma PLHIS PELOTAS, em especial o mapa participativo, permitiu um 
amplo diagnóstico habitacional do município, o que desencadeou ações mais direcionadas por parte do Poder Público.

Assim, embora exista corrente mais pessimista no sentido que os meios eletrônicos aprofundam as diferenças (sociais) entre os que têm recurso para participar e os que não têm (BEST e KRUEGER, 2005), percebe-se que o uso de ferramentas digitais diminui os custos e otimiza o tempo daqueles que participam de algum processo deliberativo, além de promover uma espécie de aproximação entre os interlocutores, criando novos canais entre os cidadãos e organizações da sociedade civil ou entre cidadãos e as próprias autoridades políticas (MESQUITA e CANTONI, 2016), o que pode favorecer, por exemplo, reivindicações oriundas de movimentos sociais, organismos não-governamentais, e, consequentemente influenciar a elaboração de políticas públicas.

Dessa forma, pode-se inferir ainda que o uso das TICs possibilita uma aproximação entre sociedade e Estado, promovendo o exercício da cidadania em maior escala (se é possível assim dizer), em virtude da abrangência resultante dos recursos tecnológicos (participação online). Nas palavras Pérez Luño (2004), os meios tecnológicos possibilitamaos cidadãos se expressarem instantaneamente sobre seu ponto de vista, proporcionando a maximização e otimização da comunicação direta, sem quaisquer ressalvas, entre eles e os responsáveis pela tomada de decisões do poder político.

As TICs também são usadas pelos governos, no contexto das cidades inteligentes, para aumentar a legitimidade da gestão pública, numa espécie de aproximação/acesso virtual da sociedade civil. Assim, utilizar as TICs como ferramenta de participação e mobilização pode ser um caminho útil na identificação de problemas e de luta política para a construção de uma nova sociabilidade (BRUCKMANN et al, 2015). No mundo hodierno, conhecimento e informação compõem um novo paradigma de socialização, permitindo que os cidadãos possam, quase que em tempo real, saber sobre o que possa afetar suas vidas, direta ou indiretamente (WEISS, 2017, p. 812).

Portanto, as TICs, na perspectiva de cidades inteligentes, são ferramentas facilitadoras da participação social, responsáveis por fomentar a promoção do ideal democrático, à medida que envolve os cidadãos no debate sobre melhorias para a vida urbana, incluindo-os nas agendas de governo, de modo que os mesmos possam participar dos processos decisórios de definição de agenda, formulação e implementação de políticas públicas, com vistas à garantia dos direitos sociais resguardos pela Constituição Brasileira de 1988. Talvez, na perspectiva 
sustentada por este trabalho, haja uma aproximação da definição das smart cities ao conceito do direito à cidade proposto por Henri Lefebvre.

\section{REFERÊNCIAS}

ALVES, Fabiana Robles Rodrigues; BRELÀZ, Gabriela de. Participação social e uso de TICS na revisão do plano diretor estratégico da cidade de São Paulo 2013-2023. 2015. Disponível em: <http://banco.consad.org.br/handle/123456789/1304>. Acesso em: 16 jan. 2018.

BATTAUS, Danila M. de Alencar; OLIVEIRA, Emerson Ademir B. de. O Direito à Cidade: Urbanização Excludente e a Política Urbana Brasileira. In Revista Lua Nova. São Paulo, 97: 81-106, 2016. Disponível em: <http://www.scielo.br/pdf/ln/n97/0102-6445-In-97-00081.pdf>. Acesso em: 12 jan. 2018.

BERCOVICI, Gilberto. Dilemas do estado federal brasileiro. Porto Alegre: Livraria do Advogado, Ed. 2004.

BEST, Samuel J.; KRUEGER, Brian S. Analyzing the Representativeness of Internet Political Participation. Political Behavior 27:183-216. 2005.

BRABHAM, D. C. Crowdsourcing the Public Participation Process for Planning Projects. 2009. In: BUGS, Geisa. Tecnologias da Informação e Comunicação, Sistemas de Informação Geográfica e a participação pública no planejamento urbano. 2014. 374 f. Tese (Doutorado em Planejamento Urbano e Regional) - Faculdade de Arquitetura e Urbanismo, Universidade Federal do Rio Grande do Sul, Porto Alegre, $2014 . \quad$ Disponível em: <http://www.lume.ufrgs.br/handle/10183/112006>. Acesso em: 16 jan. 2018.

BRASIL. Constituição (1988). Constituição da República Federativa do Brasil. Brasília, DF: Senado, 1988.

BRASIL. IBGE. Acesso à Internet e à Televisão e Posse de Telefone Móvel Celular para Uso Pessoal, $2015 . \quad$ Disponível em: <https://www.ibge.gov.br/busca.html?searchword=celular\&searchphrase=all>. Acesso em: 12 jan. 2018.

BRUCKMANN, M.; ROEDEL, D.; BEVILAQUA, A. P.; GAMA, Z.; GERMANO, P.; TARRIT, F.; FERREIRA, E. S.; ALCANTARA, D. M.; FERREIRA, D. M.; PIRES, A. C. A.; FERREIRA, W. R. V.; SILVA, J. A. A.; RAMOS, V.. A participação social mediada pelas tecnologias de informação e comunicação-TIC. Revista Ciência \& Luta de Classes, v. 2, p. 16-24, 2015.

BUGS, G; RAUBER, A; ISOLAN, F, B. Ferramentas SIG para o Planejamento Participativo. In: FURTADO, Adriana; PEREIRA, André Luis; PARENZA, Cidriana; RANGEL, Rodrigo Rodrigues; BASSANI, Valéria. (Org.). Democracia nas Cidades e as Grandes Transformações Urbanas. 1ed.Porto Alegre: 2015, v. , p. 223-234.

CASTRO, Renato de. Smart Brazil - Tropicalizando o conceito de cidades inteligentes. 2015. Revista Fonte. Cidades inteligentes, práticas colaborativas. Tecnologia da Informação na Gestão 
Pública. ISSN 1808-0715. Ano 12 - Número 15. Dezembro 2015/Janeiro 2016. PRODEMGE. Disponível em: <https://www.prodemge.gov.br/images/com_arismartbook/download/17/revista_15.pdf>. Acesso em: 15 mai. 2018.

FAUSTO, B (Org.). História Geral da Civilização Brasileira. Tomo III, volume 10. Rio de Janeiro: Editora Bertrand Brasil Ltda., 2007a.

FERNANDES, Edésio. 2007. "Constructing the 'right to the city' in Brazil". Social \& Legal Studies, v.16, n.2, pp.201-19.

FERREIRA, Valéria Corrêa Silva. Cidade e democracia: o espaço urbano, os direitos fundamentais e um novo conceito de cidadania. In: Âmbito Jurídico, Rio Grande, XV, n. 103, ago. 2012.

GAMA, Kiev; ALVARO, Alexandre; PEIXOTO, Eduardo. Em Direção a um Modelo de Maturidade Tecnológica para Cidades Inteligentes. Simpósio Brasileiro de Sistemas de Informação, p. 150155, 2012.

GOBBI, Leonardo Delfim. Urbanização brasileira. Disponível em: <http://educacao.globo.com/geografia/assunto/urbanizacao/urbanizacao-brasileira.html>. Acesso em: 02 jan. 2018.

GUIMARÃES, Patrícia Borba Vilar; XAVIER, Yanko. M. de Alencar. Smart cities e Direito: conceitos e parâmetros de Investigação da governança urbana contemporânea. Direito da Cidade, v. 8, p. 1362-1380, 2016.

GUIMARÃES, Virgínia Totti. Direito à cidade e direitos na cidade: integrando as perspectivas social, política e jurídica. DIREITO DA CIDADE, v. 9, p. 626-665, 2017.

HARVEY, David. O Direito à cidade. A qualidade da vida urbana virou uma mercadoria. Há uma aura de liberdade de escolha de serviços, lazer e cultura - desde que se tenha dinheiro para pagar. Edição 82. Julho de 2013. Tribuna livre da luta de classes. Revista Piauí. Disponível em: <http://piaui.folha.uol.com.br/materia/o-direito-a-cidade/>. Acesso em: 12 jan. 2018.

HARVEY, David. O Direito à cidade. Lutas Sociais, n. 29, jul./dez., São Paulo, 2012; p. 73-89.

ITU-T Focus Group on Smart Sustainable Cities (FG-SSC). 2014. In: CAMARA, InaraPagnussat; MOSCARELLI, Fernanda Cruz. O planejamento urbano como instrumento para cidades inteligentes. In: $5^{\circ}$ Seminário Internacional de Construções Sustentáveis, 2016, Passo Fundo. Disponível em: <https://www.imed.edu.br/Uploads/5_SICS_paper_105.pdf>. Acesso em: 15 jan. 2018.

KOMNINOS, N. Cidades Inteligentes - Sistemas de Inovação e Tecnologias da Informação ao serviço do Desenvolvimento das Cidades. 2008. In: CURY, Mauro José Ferreira; MARQUES, Josiel Alan Leite Fernandes. A Cidade Inteligente: uma reterritorialização / Smart City: A reterritorialization. Redes (Santa Cruz do Sul. Online), v. 22, p. 102, 2017.

LEFEBVRE, Henri. [1968] 2008. O direito à cidade. In: TRINDADE, Thiago Aparecido. Direitos e cidadania: reflexões sobre o direito à cidade. Lua Nova (Impresso), v. 87, p. 139-165, 2012. 
LEFEBVRE, Henri. O direito à cidade. São Paulo: Centauro, 2001.

LIBÓRIO, Daniela Campos, SAULE JÚNIOR, Nelson. Princípios e instrumentos de política urbana. Enciclopédia jurídica da PUC-SP. Celso Fernandes Campilongo, Álvaro de Azevedo Gonzaga e André Luiz Freire (coords.). Tomo: Direito Administrativo e Constitucional. Vidal Serrano Nunes Jr., Maurício Zockun, Carolina Zancaner Zockun, André Luiz Freire (coord. de tomo). 1. ed. São Paulo: Pontifícia Universidade Católica de São Paulo, 2017. Disponível em: $<$ https://enciclopediajuridica.pucsp.br/verbete/76/edicao-1/principios-e-instrumentos-depolitica-urbana>. Acesso em: 12 jan. 2018.

MESQUITA, Nuno Coimbra; CANTONI, Stefania Lapolla. Participação Política Online vs. Offline no Brasil. In: MESQUITA, N. C.. (Org.). Brasil, 25 anos de Democracia: Participação, Sociedade Civil e Cultura Política. 1a ed. Rio de Janeiro: Fundação Konrad Adenauer, 2016, p. 123-143.

MOLINARO, Carlos Alberto. Direito à Cidade e o Princípio de Proibição de Retrocesso. Revista: Direitos Fundamentais \&Justiça, n. 10, Jan-Mar. 2010, p. 10.

MOURA, Emerson Affonso da Costa. As Políticas Públicas Urbanas Brasileiras e a Gestão Democrática: O Controle Social na Efetivação do Direito da Cidade. Revista de Direito da Cidade, v. 8, p. 1064, 2016.

NABUCO, Ana Luiza; MACEDO, Ana Lúcia; FERREIRA, Rodrigo Nunes. A experiência do Orçamento Participativo Digital em Belo Horizonte: o uso das Novas Tecnologias no fortalecimento da Democracia Participativa. Revista IP - Informática Pública, Belo Horizonte, a. 11, v. 1, p. 139-155, 2009.

PELOTAS. Prefeitura Municipal de Pelotas - PLHIS, Plano Local de Habitação de Interesse Social de Pelotas. Pelotas, 2013. Disponível em: <http://plhispelotas.blogspot.com.br/> e Disponível em: $<$ http://www.pelotas.rs.gov.br/noticias/detalhe.php?controle=MjAxMyOwNiOxNQ==\&codnot icia=34439>. Acesso em: 15 jan. 2018.

PEREZ LUÑO, Antonio-Enrique. Ciberciudadaní@ o ciudadaní@.com? Barcelona: Gedisa Editorial, 2004.

PALIOLOGO, Nicholas Arena; GOMES, Daniel Machado. Direito à cidade e políticas públicas para a smart city. Revista de Direito Urbanístico, Cidade e Alteridade; e-ISSN: 2525-989X; Brasília; v. 3, n. 1, p. 19-35, 2017.

PORTILHO, R. M. R.; SOUSA, R. J. L. A Tecnologia, o Capitalismo e as Novas Morfologias do Trabalho em Perspectiva. In: CONPEDI; UFPB. (Org.). Direito do Trabalho I. 1 ed. Florianópolis: CONPEDI, 2014, v. 1, p. 162-183.

ROLNIK, Raquel. A cidade e a lei: legislação, política urbana e territórios na cidade de São Paulo. São Paulo: Studio Nobel, 1997.

SANTIN, Janaína Rigo. O Estatuto da Cidade e a Gestão Democrática Municipal. Interesse Público, Porto Alegre, v. 21, p. 220-229, 2003. 
SANTIN, Janaína Rigo; MARAGON, Elizete Gonçalves. O estatuto da cidade e os instrumentos de política urbana para proteção do patrimônio histórico: outorga onerosa e transferência do direito de construir. História (São Paulo. Online), v. 27, p. 89-109, 2008.

SCHENK E., GUITTARD C. Unetypologie des pratiques de Crowdsourcing :l'externalisationvers la foule, au-delà du processusd'innovation. Strasbourg, Management International, 2012. Disponível em <http://id.erudit.org/iderudit/1012395ar>. Acesso em: 15 jan. 2018.

SELADA, Catarina. Direito à cidade (inteligente). Smart cities - Cidades Sustentáveis. 2017. Disponível em: <http://www.smart-cities.pt/pt/noticia/direito-a-2704-cidade/>. Acesso em: 16 jan. 2018.

SMART CITIES. Panorama setorial da. Internet. Setembro | 2017. Ano 9 - Número 2. Smart cities: Tecnologias de informação e comunicação e o desenvolvimento de cidades mais sustentáveis e resilientes. Disponível em: <https://nic.br/media/docs/publicacoes/6/panorama_setorial_ano-ix-n-2-smart-cities.pdf>. Acesso em: 12 jan. 2018.

SOUPIZET, Jean François. Cidades Inteligentes: desafios para as sociedades democráticas. Rio de Janeiro: Centro Edelstein de Pesquisas Sociais, 2017. São Paulo: Fundação Fernando Henrique Cardoso, 2017. 70 p. ISBN: 978-85-92661-04-5.

SOUSA, Paulo Victor Barbosa de. Mapas colaborativos na Internet: um estudo de anotações espaciais dos problemas urbanos. Dissertação (Mestrado) - Programa de Pós-Graduação em Comunicação e Cultura Contemporâneas, Universidade Federal da Bahia, Salvador, 2012. 168 p. Disponível em: <https://repositorio.ufba.br/ri/bitstream/ri/5963/1/Paulo\%20Victor\%20\%20Mapas\%20Colaborativos\%20na\%20Internet.pdf > Acesso em: 15 jan. 2018.

STRAPAZZON, Carlos Luiz. Convergência tecnológica nas políticas urbanas: pequenas e médias "cidades inteligentes". Convergência Tecnológica nas Políticas Urbanas. Curitiba, n. 22, Temática n. 6, p. 89-108, 2009.

TARTARUGA, Iván G. Peyré. Innovacionessociales e inclusivas: límites y posibilidades para eldesarrollo territorial enel contexto de laglobalización. Porto Alegre: FEE, 2016 (Textos para Discussão FEE, n. 146). Disponível em: <https://www.fee.rs.gov.br/tedes/innovaciones-socialese-inclusivas-limites-y-posibilidades-para-el-desarrollo-territorial-en-el-contexto-de-laglobalizacion/> Acesso em: 12 jan. 2018.

TAVORALI, Bianca. Direito á cidade: uma trajetória conceitual. Novos Estudos CEBRAP, no 104, p. 93-109, mar. 2016.

TRINDADE, Thiago Aparecido. Direitos e cidadania: reflexões sobre o direito à cidade. Lua Nova (Impresso), v. 87, p. 139-165, 2012.

WEISS, Marcos Cesar. Os desafios à gestão das cidades: uma chamada para a ação em tempos de emergência das cidades inteligentes no Brasil. Revista de Direito da cidade, v. 9, p. 788-824, 2017. 
WORLD URBANIZATION PROSPECTS. 2014 Revision. 2014. In: CAMARA, InaraPagnussat; MOSCARELLI, Fernanda Cruz. O planejamento urbano como instrumento para cidades inteligentes. In: $5^{\circ}$ Seminário Internacional de Construções Sustentáveis, 2016, Passo Fundo. Disponível em: <https://www.imed.edu.br/Uploads/5_SICS_paper_105.pdf>. Acessoem: 15 jan. 2018.

Trabalho enviado em 16 de março de 2018.

Aceito em 22 de maio de 2018. 